\title{
Alpha methyldopa induced hepatotoxicity in pregnancy
}

\author{
Padmasri Ramalingappa ${ }^{1}$, Hema V. Aradhya ${ }^{1}$, \\ Nagabushan Hanumantharaya ${ }^{2}$, Priyadarshini Bolarigowda ${ }^{1}$
}

\author{
${ }^{1}$ Department of Obstetrics \& Gynaecology, Sapthagiri Institute of Medical Sciences and Research Centre, Bangalore, \\ Karnataka, India \\ ${ }^{2}$ Department of Pharmacology, Mandya Institute of Medical Sciences, Mandya, Karnataka, India
}

Received: 26 June 2014

Accepted: 1 July 2014

\section{*Correspondence:}

Dr. Padmasri Ramalingappa,

E-mail: drpadmasuraj@gmail.com

(C) 2014 Ramalingappa P et al. This is an open-access article distributed under the terms of the Creative Commons Attribution Non-Commercial License, which permits unrestricted non-commercial use, distribution, and reproduction in any medium, provided the original work is properly cited.

\begin{abstract}
We report a case of gestational hepatitis due to alpha-methyldopa and briefly review the literature on alphamethyldopa-induced hepatotoxicity in pregnancy. A 32 year old woman, primigravida with 34 weeks of gestation with pre eclampsia, presented with symptoms of nausea, dark coloured urine and jaundice. She was on alpha methyldopa (Aldomet) $250 \mathrm{mg}$ thrice a day since the last five weeks. Laboratory investigations revealed raised bilirubin, serum aspartate transaminases and serum alanine transaminases. Platelets were normal. Peripheral smear did not show haemolysis. With the exclusion of viral, haemolytic and obstructive causes, drug induced jaundice was considered as a differential diagnosis. Alpha methyldopa was withdrawn and replaced with nifedipine for her pre eclampsia treatment. Her repeat bilirubin level done two weeks later showed a drop. She went into labour at 38 weeks and delivered vaginally. In postpartum follow up her liver tests returned to normal in two weeks, about six weeks after stopping methyldopa. Hepatotoxicity should be considered as one of the adverse drug reaction of alpha methyldopa. It is not possible at present to predict which patients will develop liver disease following the administration of this drug. An awareness of the possibility of methyldopa induced hepatotoxicity should be present in the clinician's mind and liver function tests should be done at regular intervals. The occasional occurrence of this harmful side effect is not a contraindication to the use of this antihypertensive agent.
\end{abstract}

Keywords: Alpha methyldopa, Hepatotoxicity, Pregnancy

\section{INTRODUCTION}

Drug-induced hepatotoxicity, also called drug-induced liver injury or drug-induced liver disease is injury to the liver that is associated with impaired liver function caused by exposure to a drug. Adverse drug reactions have to be considered as one of the major causes of iatrogenic disease. Many adverse reactions are predictable \& preventable, but there are many other adverse reactions that cannot be predicted or prevented largely because one does not understand why, how and in whom they occur. Methyldopa (L- $\alpha$-Methyl-3, 4dihydroxyphenylalanine) is a centrally acting sympatholytic agent (selective for $\alpha 2$-adrenergic receptors agonist) that reduces sympathetic drive to the heart and peripheral circulation, leading to decreased cardiac output and lowered peripheral arterial resistance. It was introduced by Oates and his co-workers more than 50 years ago for the treatment of hypertension. Over the years it has been replaced by newer classes of antihypertensives in the general population. Nevertheless, during pregnancy it is still the first line agent in treating non complicated pregnancy induced hypertension. ${ }^{1,3}$ Its advantages include the ability to maintain the reduction of blood pressure while the patient is in the recumbent position and the relative 
absence of orthostatic hypotension. The drug has a halflife of 2 hours with a bioavailability of $42 \%$. Methyldopa sulphate is the most abundant metabolite recorded. ${ }^{2}$ It is known to cause mild or reversible but not invariably benign liver disease. Reactive hepatitis is severe, uncommon reported side effect. We present here a case of methyldopa induced hepatotoxicity in pregnancy.

\section{CASE REPORT}

A 32 year old woman presented with symptoms of nausea, dark coloured urine and jaundice. She was a primigravida with 34 weeks of gestation with pre eclampsia. She was on alpha methyldopa (Aldomet) $250 \mathrm{mg}$ thrice a day since the last five weeks. There was no history of blurring of vision, vomiting, epigastric pain or headache. She gave no history of blood transfusion, allergy to other drugs or change in colour of stools. On examination she was afebrile. There was no pallor. She was deeply jaundiced. Blood pressure was 130/90 $\mathrm{mmHg}$. On per abdomen examination liver was not palpable. Uterus corresponded to 32 weeks gravid uterine size and was relaxed. Foetal heart was regular. On per vaginum examination cervix was soft, mid position, uneffaced and os closed. Laboratory investigations revealed raised bilirubin, serum aspartate transaminases and serum alanine transaminases. Serum bilirubin was 16 $\mathrm{mg} / 100 \mathrm{ml}$. Aspartate transaminase level at that time was 101 units $/ \mathrm{ml}$. The alanine transaminase was 89 units $/ \mathrm{ml}$. Alkaline phosphatase levels were mildly elevated. Platelets were normal. Peripheral smear did not show haemolysis. There was no exposure to other hepatotoxic drugs. Tests for hepatitis A, B and C were negative. Renal parameters were within normal range. With the exclusion of viral, haemolytic and obstructive causes, drug induced jaundice was considered as a differential diagnosis. Alpha methyldopa was withdrawn and replaced with nifedipine for her pre eclampsia treatment. Her repeat bilirubin level done two weeks later showed a drop by $5.1 \mathrm{mg} / 100 \mathrm{ml}$ (Table 1). Bilirubin, aspartate transaminase, alanine transaminase levels done at third and fourth week after discontinuation of methyldopa showed a consistent drop. She went into labour at 38 weeks and delivered vaginally. She had mild postpartum haemorrhage which was controlled by prostaglandins and injection vitamin $\mathrm{K}$. In postpartum follow up her liver tests returned to normal in two weeks, about six weeks after stopping methyldopa.

Table 1: Laboratory values.

\begin{tabular}{|llllll|}
$\begin{array}{l}\text { Time after starting } \\
\text { methyldopa }\end{array}$ & $\begin{array}{l}\text { Time after stopping } \\
\text { methyldopa }\end{array}$ & $\begin{array}{l}\text { Aspartate } \\
\text { transaminase } \\
\text { (U/L) }\end{array}$ & $\begin{array}{l}\text { Alanine } \\
\text { transaminase } \\
(\mathrm{U} / \mathrm{L})\end{array}$ & $\begin{array}{l}\text { Serumbilirubin } \\
(\mathrm{mg} / \mathrm{dL})\end{array}$ & $\begin{array}{l}\text { Alkaline } \\
\text { phosphatase } \\
\text { (U/L) }\end{array}$ \\
\hline & 101 & 89 & 16 & 155 \\
\hline & 2 weeks & 83 & 66 & 10.9 &.. \\
\hline \\
\hline
\end{tabular}

\section{DISCUSSION}

The association of hepatocellular dysfunction with administration of Aldomet, first recorded by Gillespie in 1960 was subsequently been observed by many workers. Elkington SG and colleagues in 1969 unequivocally established the relationship between alpha methyldopa and liver damage in a hypertensive black male patient. The patient developed jaundice within a week of starting the drug. Over a period of time the drug was withdrawn and re administered with remission and recurrence of symptoms. Each successive relapse was clinically and biochemically less severe than the preceding one showing desensitisation can be achieved with repeated dosages. Rarely, however, such a procedure is known to cause irreversible fulminant hepatic necrosis and death. The clinical syndrome has usually shown similarities to viral hepatitis with prompt recovery on stopping treatment. ${ }^{4}$ In our case the drug was not re administered in view of safety for both the mother and foetus. Picaud A and workers reported a case of toxic hepatitis in a woman of 22 years of age in the third trimester of her first pregnancy, treated with methyldopa for hypertension of pregnancy which was diagnosed at 33 weeks of amenorrhoea. The outcome was fatal. The patient died three days after delivery following haematemesis and renal failure as well as hepatic encephalopathy. ${ }^{5}$ Mortality has been found usually in patients aged over forty. Fortunately, our patient recovered from the drug reaction and has been doing well. Both minor and severe forms of liver damage have been reported in patients receiving methyldopa for the treatment of hypertension. The former consists of asymptomatic and often transient rise in serum transaminases. ${ }^{6}$ The abnormalities usually manifest within four weeks of starting the drug. The clinically overt and more severe forms of hepatotoxicity are encountered much less frequently and become apparent after five or more years of drug ingestion. The 
mechanism by which it causes hepatic injury is unpredictable. The dosage of methyldopa appears irrelevant in precipitation of the disorder. It may be associated with other signs of hypersensitivity such as fever, rash, eosinophilia or a positive direct Coombs test. It appears only in a small fraction of exposed persons, many of whom have a positive history of allergy. The hepatic injury has rarely been reproduced in experimental animals. ${ }^{7}$ It may not always be due to hypersensitivity as in the lethal case described by Picaud, where the toxic hepatitis was a combination of abnormal metabolism (the cytochrome $\mathrm{P} 450$ chain produces an antigen) and autoimmune mediated hepatocyte injury in response to this antigen and these explain why such severe and potentially fatal forms of the condition exist. The histologic pattern observed in these patients varies from parenchymatous degeneration, focal, confluent, necrosis and inflammation with short term exposure. Fatty infiltration and fibrous trabeculae is seen on long term use. Methyldopa is a category B drug with established record of safety during pregnancy and breast feeding. ${ }^{8}$ Though this drug has been the most frequently assessed antihypertensive in randomised trials and has the longest safety track record, ${ }^{1}$ one has to keep a vigil on possibilities of hepatotoxicity. Uterine artery Doppler in women on alpha methyldopa therapy for hypertensive disorders of pregnancy shows the medication does not impair normal uteroplacental circulation. ${ }^{9}$ While no long term effects on the foetus or neonate have been reported with methyldopa administered to the mother it is found in the infant at birth, at a level comparable to maternal level and persists for some days after birth. It can be an infrequent cause for new-born hyperbilirubinaemia with positive Coombs' test and without blood group incompatibility due to drug induced development of $\operatorname{IgG}$ auto antibodies against red blood cells which can cross the placenta and cause haemolysis. ${ }^{10}$

\section{CONCLUSION}

Alpha-methyldopa is one of the most widely prescribed antihypertensive agents used during pregnancy. It is still the first line agent in treating non complicated pregnancy induced hypertension. Jaundice has been reported as a rare complication of methyldopa therapy, and abnormalities in liver function tests are occasionally found in patients taking the drug.
Funding: No funding sources Conflict of interest: None declared

Ethical approval: Not required

\section{REFERENCES}

1. James PR, Nelson-Piercy C. Management of hypertension before, during, and after pregnancy. Heart. 2004;90:1499-504.

2. Skerjanec A, Campbell NR, Robertson S, Tam YK. Pharmacokinetics and presystemic gut metabolism of methyldopa in healthy human subjects. J Clin Pharmacol. 1995;35(3):275-80.

3. Godosis D, Komaitis S, Tziomalos K, Baltatzi M, Ntaios G, Savopoulos CG, Hatzitolios, AI. Cardiovascular diseases in pregnancy. Am $\mathbf{J}$ Cardiovasc Dis. 2012;2(2):96-101.

4. Elkington SG, Schreiber WM, Conn HO. Hepatic injury caused by L-alpha-methyldopa. Circulat. 1969;40:589-96.

5. Picaud A, Walter P, de Préville G, Nicolas P. Fatal toxic hepatitis in pregnancy. A discussion of the role of methyldopa. J Gynaecol Obstet Biol Reprod. 1990;19(2):192-6.

6. Rodman JS, Deutsch DJ, Gutman SI. Methyldopa hepatitis. A report of six cases and review of the literature. Am J Med. 1976;60(7):941-8.

7. Carstairs KC, Breckenridge A, Dollery CT, Worlledge SM. Incidence of a positive direct Coombs test in patients on alpha-methyldopa. Lancet. 1966 Jul 16;2(7455):133-5.

8. Vest AR, Cho LS. Hypertension in pregnancy. Cardiol Clin. 2012;(30):407-23.

9. Khalil A, Harrington K, Muttukrishna S, Jauniaux E. Effect of antihypertensive therapy with alphamethyldopa on uterine artery Doppler in pregnancies with hypertensive disorders. Ultrasound Obstet Gynaecol. 2010;35(6):688-94.

10. Ozdemir OM, Ergin H, Ince T. A newborn with positive antiglobulin test whose mother took methyldopa in pregnancy. Turk $\mathrm{J}$ Paediatr. 2008;50(6):592-4.

DOI: $10.5455 / 2320-1770 . i j r \operatorname{cog} 20140938$

Cite this article as: Ramalingappa $\mathrm{P}$, Aradhya HV, Hanumantharaya N, Bolarigowda P. Alpha methyldopa induced hepatotoxicity in pregnancy. Int J Reprod Contracept Obstet Gynecol 2014;3:805-7. 